\title{
Influence of precipitation changes on the SPI and related drought severity. An analysis using long-term data series
}

3 Ana Paulo $^{1,3, *}$, Diogo Martins ${ }^{2}$, Luís Santos Pereira ${ }^{3}$

4

${ }^{1}$ ESAS, Instituto Politécnico de Santarém, Portugal

${ }^{2}$ Instituto Dom Luiz, Faculdade de Ciências, DEGGE, Universidade de Lisboa, Lisboa, Portugal

${ }^{3}$ LEAF - Research Center on Landscape, Environment, Agriculture and Food, Instituto Superior de Agronomia, Universidade de Lisboa, Portugal

* corresponding author, ambrosio.paulo@gmail.com

Abstract: Drought indices, such as the Standardized Precipitation Index (SPI) are used to quantify drought severity. Due to the SPI probabilistic and standardized nature, a given value of SPI computed in distinct time periods or locations indicates the same relative drought severity but corresponds to different amounts of precipitation. Thus, the present study aims at contributing for a comprehensive analysis of the influence of long-term precipitation variability on drought assessment by the SPI. Long records of monthly precipitation, spanning from 1863 to 2007 in several locations across Portugal, were divided into 30 years sub-periods and the SPI with 12-month time scale (SPI-12) was computed for each sub-period and for the entire period of records. The probability distributions adjusted to precipitation in those different time periods were compared envisaging to detect the SPI sensitivity to the reference period and, therefore, to changes in precipitation. Precipitation thresholds relative to the upper limits of SPI-12 drought categories were obtained and the influence of the time period was investigated. Results have shown that when SPI values derived from the full data record for a recent time period are lower/higher than the SPI values derived from data of the considered time period a recent downward/upward shift of precipitation has occurred. Coherently, a common pattern of drought aggravation from the initial until the more recent period was not detected. However, in southern locations, lower precipitation thresholds of the SPI drought categories were generally found in the more recent period, particularly for more severe drought categories, whereas in the northern locations Porto and Montalegre, an increase was detected. The impacts of the reference period on the computed SPI drought severity and frequency are shown, bringing to discussion the need for updating 'normal' conditions when long term precipitation records are available and precipitation changes are observed. 
Key words: SPI; precipitation thresholds; drought severity; reference periods; Portugal.

\section{Introduction}

Drought is a natural temporary imbalance of water availability, consisting of a persistent lowerthan-average precipitation, of uncertain frequency, duration and severity, of unpredictable or difficult to predict occurrence, resulting in diminished water resources availability and carrying capacity of the ecosystems (Pereira et al., 2009). There are numerous definitions for drought and its perception varies with the water sectors affected, and its frequency or severity may be aggravated by climate change.

Standardized drought indices computed from precipitation, evapotranspiration, streamflow or soil moisture have been used to monitor drought and to quantify drought severity. The standardized precipitation index (SPI) is the most widely used. SPI values quantify deviations from 'normal precipitation' (McKee et al., 1993). SPI values are classified in drought (wetness) categories, with the more negative values indicating a more severe drought category (McKee et al., 1995). The World Meteorological Organization recommends its inclusion in drought monitoring systems since 2009 (WMO, 2012). As a result of the evaluation of drought indices in the quantification of meteorological drought using a combined pool of criteria (Keyantash and Dracup, 2002), the SPI is surpassed by rainfall deciles in transparency and by cumulative precipitation anomalies in dimensionality. Transparency refers to the way an index of drought is understandable by the scientists, stakeholders and the public, and dimensionality refers to the link of the index to a physical quantity. The index is obtained from the adjustment of a probability distribution function (pdf) to the precipitation cumulated over a given number of months denoted as time scale. Shorter time scales are appropriate to monitor the effects of precipitation shortages in soil water storage and agriculture, while longer time scales are used to monitor drought effects on surface and ground water resources.

Despite SPI is the most used in Portugal, other drought indices have also been used in the country, namely the Palmer Drought Severity Index (PDSI, Palmer, 1965), which combines precipitation and evapotranspiration to define a deviation from normal through a soil water balance, and a modification of the PDSI (MedPDSI, Pereira et al., 2007) to better perform the soil water balance using an olive crop as standard perennial crop (Paulo et al., 2012).

Moreira et al. (2012) reviewed numerous studies aimed at detecting any possible aggravation of drought frequency and severity in Portugal and in the Iberian Peninsula showing non-increasing trends for northern Iberia and varied trends for central and southern regions. Those authors investigated the temporal drought aggravation applying generalized log-linear models and statistical inference to long time series and their decomposition into sub-periods using the SPI. Their results 
did not support the assumption of a trend of drought aggravation that could be related to climate change but cycles corresponding to the considered sub-periods where drought was more frequent and severe followed by others where frequency and severity were lower. However, comparing the last period of 27 years with the precedent one they concluded that drought occurrence and severity increased during that last period with exception of the northern region. The studies by Santos et al. (2010), Martins et al. (2012), Paulo et al. (2012) and Raziei et al. (2015) did not evidence trends for either an increase or decrease of drought occurrence or severity in most of the country. De Lima et al. (2010) studied trends for precipitation in Portugal using long data sets, ranging between 88 and 145 years and did not found a generalized significant long term pattern of change but a sequence of alternating periods of decreasing and increasing trends in both annual and monthly precipitation, which were sometimes statistically significant. The results by Moreira et al. (2012) were in the same line. The analysis of trends and correlation in annual extreme precipitation indices (de Lima et al., 2015) led to conclude that there is an important but not statistically significant decrease in regional average annual precipitation.

Due to its standardized nature, the same negative SPI value computed in different locations or time periods corresponds to the same relative drought severity but to different amounts of precipitation. The relative measure provided by the SPI would be more transparent if accompanied by an absolute value of the monthly precipitation thresholds relative to the SPI drought categories as shown by Paulo and Pereira (2008) and Portela et al. (2012). However, the SPI depends on the pdf adopted, on the method used for parameter estimation and on the reference time period used in the estimation. Although some authors advocate the Pearson III distribution (Guttman, 1999; Vicente-Serrano, 2006) the gamma distribution is the more common worldwide and has been adopted in various Portuguese studies following previous tests (Paulo et al., 2003; Paulo and Pereira, 2006). However, the precipitation thresholds relative to the severity drought categories were already considered (Paulo and Pereira, 2008) and may consist of a first step for the application of the SPI to future precipitation scenarios.

Impacts of future climates on aridity and drought have been addressed by several authors using the SPI and several modifications to this index (Loukas et al., 2008; Dubrovsky et al. 2009; Dai 2011; Sienz et al. 2012; Russo et al. 2013; Jeong et al. 2014; Zargar et al. 2014; Zarch et al. 2015). Loukas et al. (2008) computed the SPI in Thessaly-Greece with the gamma distribution adjusted separately for the base time period 1960-1990 and for two future periods, 2020-2050 and 20702100. These authors concluded that the annual drought severity increased for the future scenarios for all target hydrological areas. However, they did not consider possible differences in the precipitation deficits that are associated with the severity categories. 
In the context of climate change some alterations to the SPI were proposed in relation to impacts on drought, either with the objective of comparing present conditions and future climates or to include trends in the probability model accounting for the non-stationarity in precipitation. Dubrovsky et al. (2009) proposed a relative SPI derived from a reference precipitation time series with the aim of between-stations comparison considering present climate conditions and future climates. The same authors noted that the pdf obtained for the reference period used to compute the SPI in different time periods, e.g., periods with future climate data, may lead to errors due to lack of fit of the pdf to those various periods, namely relative to the tails of the pdf curves. Russo et al. (2013) presented a new formulation of the SPI applied to model-simulated precipitation under greenhouse forcing gradual changes; precipitation outputs from climate models were modelled by a gamma distribution with the scale parameter varying linearly with time, and the modified SPI,

111 denoted as nonstationary Standardized Precipitation Index (SnsPI), was compared with the SPI 112 relative to the full period. These authors reported that SnsPI performed better than SPI to describe 113 simulated precipitation changes. Zargar et al. (2014) modified the SPI calculation with the objective 114 of modelling the effects of the shift in precipitation normals on drought frequency. These authors 115 built confidence intervals for the parameters of the gamma distribution and applied an enhanced p116 box method for studying climate change effects on SPI drought frequency. Assuming nonstationarity of at-site precipitation series, a time-dependent SPI (SPIt) was developed and applied to 118 historical records of summer precipitation in the Luanhe River basin, China (Wang et al., 2015). 119 The mean is described by a polynomial function of time and, as a result, the scale parameter of the 120 gamma distribution is time dependent. This approach is similar to the one proposed by Russo et al. 121 (2013) replacing the linear variation of the scale parameter of the gamma distribution by a polynomial variation with time.

Considering the brief review above and the need to better understanding the possible variation of the precipitation thresholds associated with the SPI categories, the present study aims to analyse the influence of precipitation changes on the SPI dynamics and on drought assessment. With this purpose, using very long precipitation data series, the gamma pdfs of precipitation, the SPI and the precipitation thresholds relative to various SPI drought categories for the entire period of observations and for various sub-periods were analysed to take into consideration actual precipitation changes.

\section{Precipitation Data and Partition in Sub-Periods}

Long records of monthly precipitation from 9 meteorological stations across Portugal (Fig.1) were used in this study. The study was conducted for locations used by Moreira et al. (2012) having monthly precipitation with at least 99 years. The data records were divided into sub-periods with a 
134 minimum record length of 30 years. The altitude and coordinates of the stations, dates of beginning 135 and ending of precipitation records, record length and duration of the first sub-period preceding 136 1911, are presented in Table 1.

137 Annual precipitation was statistically examined for homogeneity. Linear trends, autocorrelation 138 and changes in the median and in the variance were investigated through non-parametric tests. Due 139 to the uncertainty and subjectivity involved in the adjustment of a single site (Rhoades and Salinger, 140 1993), the original series were not corrected similarly to the procedure adopted by Santos et al. 141 (2010) in the analysis of spatial and temporal variability of droughts in Portugal based on 94 years 142 of precipitation data. However, positive linear trends and changes in the median and in the variance 143 of precipitation were detected in Montalegre and Faro; the first is the more northern station, located 144 at high altitude and having annual median precipitation above $1000 \mathrm{~mm}$, and the second is the more southern station, located by the coast and having an annual median precipitation below $500 \mathrm{~mm}$,

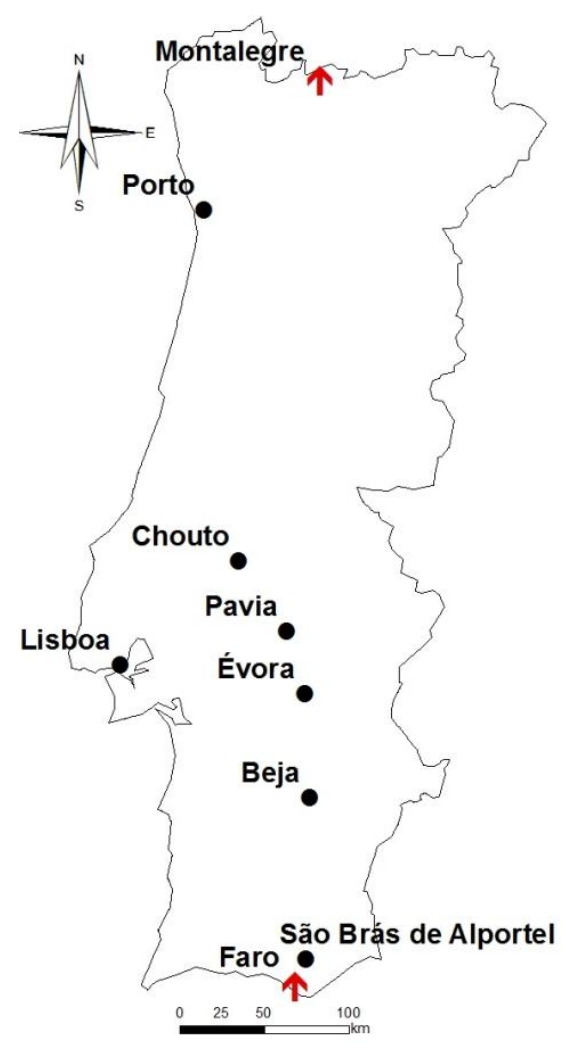

Figure 1. Location of the meteorological stations

Precipitation time series were divided into sub-periods: prior to 1911,1911 to 1943,1944 to 1975 and 1976 to 2007. The criteria adopted for this partition was based on the time series length, on drought identification with SPI in the nine stations considering the full period of records, on results of a previous study with the same data (Moreira et al. 2012), and on previous drought studies applied to southern Portugal relative to the period 1932-1999 (Paulo et al., 2003, Paulo and Pereira, 2006) and to the entire country in various periods (Santos et al. 2010; Martins et al. 2012). Main 
154 droughts were identified in those studies for the years of 1944-1945, 2004-2006, 1949 and 1980155 1981, all with a regional coverage of more than $60 \%$ of the area.

Table 1. Location of the meteorological stations, date of records, record length and duration of the first sub-period

\begin{tabular}{llllllll}
\hline \multirow{2}{*}{ Station } & $\begin{array}{l}\text { Latitude } \\
\text { (North) }\end{array}$ & $\begin{array}{l}\text { Longitude } \\
\text { (West) }\end{array}$ & Altitude (m) & From & To & Total & before 1911 \\
\hline Montalegre & 41.82 & 7.78 & 1005 & Jan 1879 & Dec 2007 & 128 & 32 \\
Porto & 41.13 & 8.60 & 93 & Jan 1863 & May 2012 & 148 & 48 \\
Chouto & 39.28 & 8.35 & 130 & Jan 1911 & Dec 2009 & 98 & - \\
Pavia & 38.90 & 8.02 & 192 & Jan 1911 & Dec 2011 & 100 & - \\
Lisboa & 38.72 & 9.15 & 77 & Jan 1871 & May 2012 & 140 & 40 \\
Évora & 38.57 & 7.90 & 309 & Jan 1870 & Jul 2012 & 141 & 41 \\
Beja & 38.02 & 7.87 & 246 & Jan 1897 & Dec 2007 & 110 & 14 \\
S.Brás de Alportel & 37.17 & 7.90 & 325 & Nov 1908 & Sep 2012 & 103 & - \\
Faro & 37.02 & 7.97 & 8 & Jan 1896 & Sep 2012 & 115 & 15 \\
\hline
\end{tabular}

160 according to the length of data records highlight differences between sub-periods and locations. The 161 boxes range from the 1 st to the 3rd quartile, the bold line represents de median and the plot 162 whiskers the extremes; the outliers are not represented. Greater median values are observed in 163 Montalegre, located at higher altitude, and Porto, both in the northern region, and also in S.Brás de 164 Alportel, in the south, located in the south downhill side of Serra do Caldeirão. 

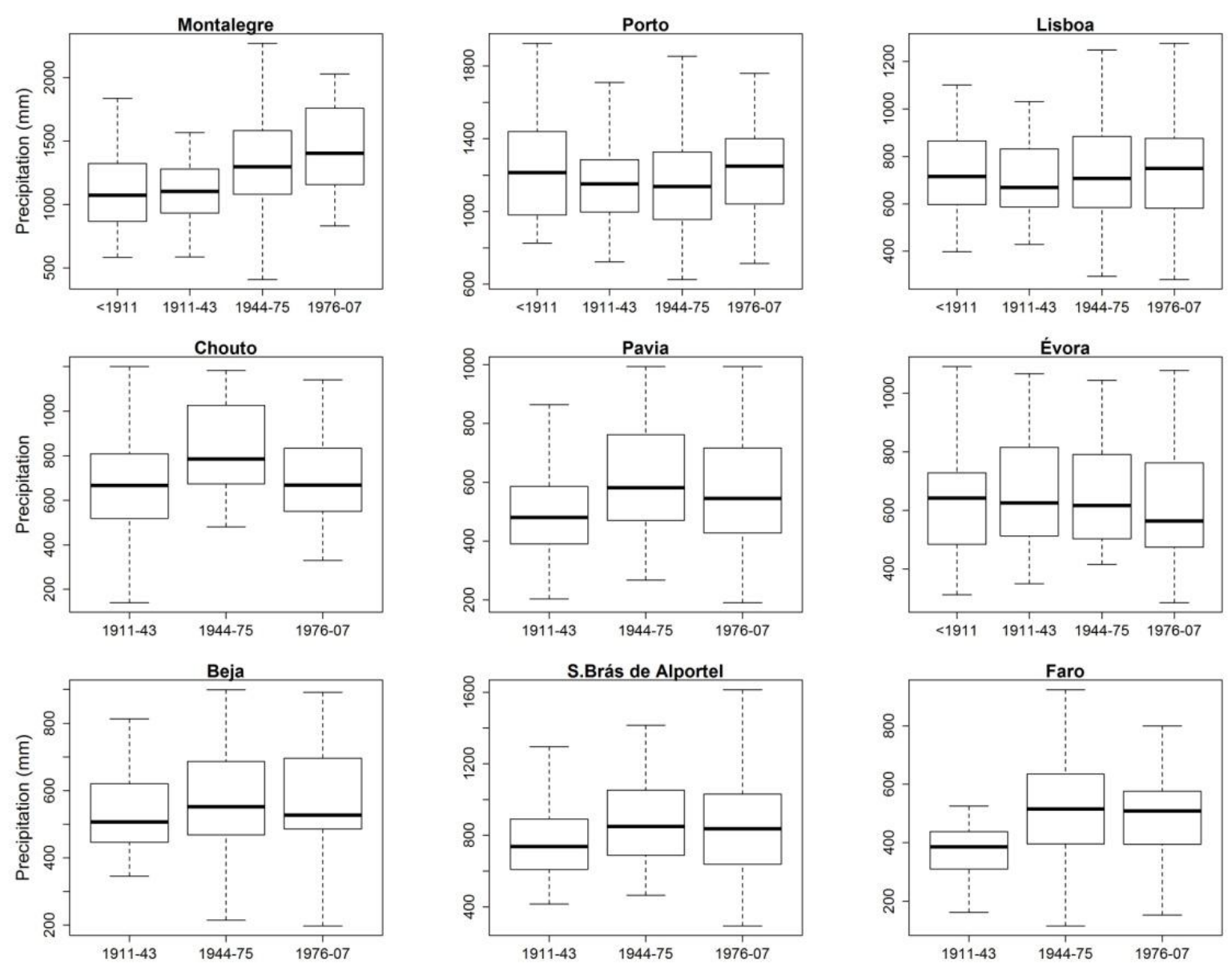

Figure 2. Annual precipitation (October to September) in 4 or 3 time sub-periods according to the length of data records

\section{Methods}

The SPI is a probabilistic drought index. A probability distribution is adjusted to the k-months cumulative precipitation, where $\mathrm{k}$ is the SPI time scale, for each calendar month. Therefore, twelve distribution functions are independently obtained. The cumulative probability associated with an observed precipitation amount is estimated from the adjusted distribution function and is then transformed into a standard normal quantile, the SPI, as described by McKee et al. (1993).

The calculation of the SPI requires the following steps (McKee et al., 1993, Bordi and Sutera, 2001, Sienz et al., 2012): two parameter gamma distribution was adopted with the probability density function defined by

$$
f(x)=\frac{1}{\beta^{\alpha} \Gamma(\alpha)} x^{\alpha-1} e^{-\frac{x}{\beta}}, x>0
$$

where $\Gamma$ is the gamma function, and $\alpha$ and $\beta$ are the shape and scale parameters. The parameters were estimated by the maximum likelihood method. 
2) Calculation of the probability for each precipitation event $p=F(x ; \hat{\alpha}, \hat{\beta})$

3) Calculation of the standard normal quantile $S P I=\phi^{-1}(p)$ where $\phi(x ; 0,1)$ is the standard normal distribution.

Assuming a perfect fit between the adjusted pdf and the empirical distribution of precipitation it is possible to identify the precipitation depths corresponding to the SPI threshold values if the distribution $\mathrm{F}(\mathrm{x})$ is known, the gamma distribution in the present application. With this purpose, the SPI value is transformed into the non-exceedance probability $\mathrm{p}$ through the normal distribution $p=\phi(S P I)$, resulting that the corresponding precipitation depth is $x=F^{-1}(p ; \hat{\alpha}, \hat{\beta})$.

Drought is classified according to SPI values. McKee et al. (1995) proposed four drought categories: near normal/mild, moderate drought, severe drought and extreme drought (Table 2). The SPI is normalized, so the cumulative probabilities relative to the upper thresholds of SPI drought categories are obtained from the normal distribution.

Table 2. Upper thresholds of SPI drought categories and respective cumulative probabilities

\begin{tabular}{lll}
\hline Drought category & SPI & Cumulative probabilities \\
\hline Mild/Near normal & 0 & 0.5000 \\
Moderate & -1 & 0.1587 \\
Severe & -1.5 & 0.0668 \\
Extreme & -2 & 0.0228 \\
\hline
\end{tabular}

The SPI provides a relative measure of drought severity, thus allowing comparisons between locations and between time periods for a given location. An SPI value in the interval $(-1.5,-2)$ is classified everywhere as a severe drought. However, a given SPI value obtained in different locations or, in the same location using a different reference period, corresponds to different precipitation deficits, i.e., the difference between the observed and the median. Therefore, the SPI index should not be used for absolute drought comparisons between stations or, for a given station, between time periods if appropriate complementary information is not available. In the present study, the SPI is not only obtained with a pdf adjusted for the complete precipitation series but it is also computed separately for each time sub-period. This approach assumes the hypothesis of coherence between precipitation observed in a given time period and the probability laws governing the occurrence of precipitation during the same period.

A 12-month time scale identifies cumulated precipitation deficiencies over a large period, is well related with the impacts of drought in water resources and is more adequate in the present study than shorter time scales (Mishra and Singh, 2010). Therefore, the SPI-12 was obtained for the nine locations and for the sub-periods defined above (Table 1 and Fig. 2) and for the full period of records. The normality of the SPI was verified in each period and calendar month through the Kolmogorov-Smirnov and the Shapiro-Wilk non-parametric tests (D'Agostino and Stephens, 1986). 
As the Shapiro-Wilk normality test does not validate the parameters of the normal distribution the approach by Wu et al. (2007), which considers that a distribution is not normal when the ShapiroWilk statistic is smaller than 0.96 , the respective p-value is smaller than 0.10 and the absolute value of the median SPI is greater than 0.05, was also used.

The moments of the gamma distribution, expected value, variance and asymmetry were obtained from the shape and scale parameters

$$
\mu=\alpha \beta ; \quad \sigma^{2}=\alpha \beta^{2} ; \quad \gamma=\frac{2}{\sqrt{\alpha}}
$$

and were estimated for the total period and the sub-periods. Differences in the parameter values between sub-periods relate to precipitation changes in the mean, variability and asymmetry, which are easier to interpret than comparing the shape and scale parameters of the gamma distribution.

The pdf curves and the histogram of precipitation for the total period and the sub-periods were plotted in the same graphics; similarly the cumulative distribution functions (cdfs) were plotted in a companion graphic to support visual comparisons.

The precipitation depths corresponding to the thresholds of the SPI categories were estimated within each time sub-period and the full period. Therefore, the near normal or mild drought category $(-1<\mathrm{SPI}<0)$ corresponds to a precipitation depth below the median $(\mathrm{SPI}=0)$ and above the threshold of moderate drought (SPI=-1); similarly, for the the moderate, severe and extreme drought. The inter-comparison of time periods was also performed by examining the precipitation thresholds corresponding to the same drought categories. If the precipitation threshold of a given drought category in the recent period is lower/higher than in the precedent time period it means that a decrease/increase in precipitation has occurred. Conversely, the precipitation thresholds in a given time period correspond to different cumulative probabilities in another time period and may be classified in a different drought category. The inter-comparison is therefore ilustrated by a zoom of the lower tail of the cdf.

The frequency of SPI categories, for the total period and sub-periods was obtained by counting the number of months in those categories and values were tabled to support the comparison between the SPIs when computed for the full data record and for each sub-period.

\section{Results}

\subsection{Changes in the gamma distribution function}

The goodness of fit tests applied to the SPI-12 have shown a good agreement with the normal distribution. The Kolmogorov-Smirnov did not reject the $\mathrm{N}(0,1)$ distribution of SPI in any time period, calendar month and location. The approach of Wu et al (2007) led to only $2.9 \%$ rejections of 
SPI-12 normality, i.e., 14 rejections in 480 tests. These results support the appropriateness of using the gamma distribution and the hypothesis of normality of the SPI-12.

It is known that changes in precipitation impact the parameters and the moments of the gamma distribution. The changes in the shape and scale parameters $\alpha$ and $\beta$ of the gamma distribution vary from period to period but differently to the various locations (Table 3). In Porto, Lisboa, Beja, S. Brás and Faro the shape parameter $\alpha$ decreases from the sub-period 1911-1943 to the last sub-period 1976-2007 while $\beta$ increases. In other locations - Chouto, Pavia and Évora - $\alpha$ is higher in the subperiod of 1944-1975 while $\beta$ varies inversely. $\alpha$ and $\beta$ behave differently for Montalegre. This means that the variability of precipitation is tied to the considered locations.

Table 3. Shape $(\alpha)$ and scale $(\beta)$ parameters of the gamma distribution fitted to the cumulated precipitation (October to September) for the full record period and the sub-periods

\begin{tabular}{|c|c|c|c|c|c|c|c|c|c|c|}
\hline Time period & $\begin{array}{l}\text { Gamma } \\
\text { parameters }\end{array}$ & Montalegre & Porto & Chouto & Pavia & Lisboa & Évora & Beja & S.Brás & Faro \\
\hline \multirow[t]{2}{*}{ Full record } & $\alpha$ & 9.60 & 14.60 & 8.31 & 8.97 & 11.38 & 11.38 & 13.30 & 8.02 & 6.83 \\
\hline & $\beta$ & 130.9 & 84.6 & 87.5 & 62.0 & 64.8 & 56.2 & 42.6 & 101.7 & 68.9 \\
\hline \multirow[t]{2}{*}{ Before 1911} & $\alpha$ & 13.34 & 12.67 & - & - & 12.55 & 10.84 & - & - & - \\
\hline & $\beta$ & 82.8 & 102.0 & - & - & 59.6 & 58.6 & - & - & - \\
\hline \multirow[t]{2}{*}{ 1911-1943 } & $\alpha$ & 17.12 & 24.69 & 5.93 & 8.41 & 18.04 & 12.48 & 16.61 & 12.43 & 9.19 \\
\hline & $\beta$ & 64.1 & 47.9 & 114.6 & 60.0 & 39.3 & 53.3 & 33.0 & 62.1 & 43.7 \\
\hline \multirow[t]{2}{*}{ 1944-1975 } & $\alpha$ & 8.25 & 14.51 & 14.79 & 12.06 & 11.18 & 15.24 & 13.47 & 10.52 & 7.15 \\
\hline & $\beta$ & 166.8 & 82.4 & 56.0 & 50.6 & 66.8 & 43.7 & 43.2 & 82.3 & 71.7 \\
\hline \multirow[t]{2}{*}{ 1976-2007 } & $\alpha$ & 10.96 & 13.99 & 11.05 & 8.69 & 9.72 & 9.47 & 9.10 & 6.96 & 5.64 \\
\hline & $\beta$ & 135.8 & 91.2 & 63.8 & 66.6 & 75.4 & 64.4 & 62.3 & 122.6 & 90.1 \\
\hline
\end{tabular}

The resulting values for the mean, the standard deviation and the coefficient of asymmetry estimated for the annual precipitation cumulated from October to September are presented in Table 4. It can be observed that the highest mean precipitation refers to 1944-75 for all seven southern stations and to the later period in case of Montalegre and Porto, in the northern region. The lowest mean values are for 1911-43 except for Évora. The mean values computed with the full period of records are generally smaller than the mean relative to 1944-75. The differences in the precipitation mean relative to the highest and lowest mean values relative to the considered sub-periods is quite large at Montalegre, $391 \mathrm{~mm}$, and small in Beja, $32 \mathrm{~mm}$. Large differences, 150 and $105 \mathrm{~mm}$, also exist for Chouto and Pavia respectively. The standard deviation is more often larger in the last period, 1976-2007 and not when the mean is larger. It can be observed that the coefficient of asymmetry is also more often larger in the sub-period 1976-2007.

The effects of the reference period on the gamma distribution relative to the 12 month cumulated precipitation October-September may be observed in the gamma pdf and cdf curves presented in Fig. 3 relative to the four stations with longer records, Montalegre, Porto, Évora and Lisboa. Necessarily the above referred differences in behaviour reflects on the differences among pdf and 
cdf curves, as for the examples in Fig. 3. The cases when the mean values largely change have quite different cdf curves among sub-periods.

Table 4. Mean, standard deviation and coefficient of asymmetry estimated from the gamma distribution fitted to the cumulated precipitation (October to September) for the full time period and the considered sub-periods

\begin{tabular}{lllllllllll}
\hline Estimates of & Time period & Montalegre & Porto & Chouto & Pavia & Lisboa & Évora & Beja & S.Brás & Faro \\
\hline \multirow{2}{*}{ Mean } & Full records & 1257 & 1236 & 728 & 556 & 737 & 640 & 566 & 816 & 471 \\
& Before 1911 & 1104 & 1292 & - & - & 748 & 635 & - & - & - \\
& $1911-1943$ & 1097 & 1182 & 679 & 504 & 708 & 665 & 548 & 773 & 402 \\
& $1944-1975$ & 1376 & 1195 & 829 & 609 & 748 & 666 & 582 & 866 & 513 \\
& $1976-2007$ & 1488 & 1276 & 706 & 579 & 732 & 610 & 567 & 853 & 509 \\
\hline \multirow{2}{*}{ Std. deviation } & Full records & 406 & 323 & 252 & 186 & 219 & 190 & 155 & 288 & 180 \\
& Before 1911 & 302 & 363 & - & - & 211 & 193 & - & - & - \\
& $1911-1943$ & 265 & 238 & 279 & 174 & 167 & 188 & 135 & 219 & 133 \\
& $1944-1975$ & 479 & 314 & 215 & 176 & 224 & 171 & 158 & 267 & 192 \\
& $1976-2007$ & 450 & 341 & 212 & 196 & 235 & 198 & 188 & 323 & 214 \\
\hline \multirow{2}{*}{ Coef. asymmetry } & Full records & 0.65 & 0.52 & 0.69 & 0.67 & 0.59 & 0.59 & 0.55 & 0.71 & 0.77 \\
& Before 1911 & 0.55 & 0.56 & - & - & 0.56 & 0.61 & - & - & - \\
& $1911-1943$ & 0.48 & 0.40 & 0.82 & 0.69 & 0.47 & 0.57 & 0.49 & 0.57 & 0.66 \\
& $1944-1975$ & 0.70 & 0.53 & 0.52 & 0.58 & 0.60 & 0.51 & 0.54 & 0.62 & 0.75 \\
& $1976-2007$ & 0.60 & 0.53 & 0.60 & 0.68 & 0.64 & 0.65 & 0.66 & 0.76 & 0.84 \\
\hline
\end{tabular}

The pdf curves (Fig. 3) relative to the various sub-periods and the full period of records show greater differences in the northern mountainous station of Montalegre, where differences in the mean value are larger in absolute and relative terms. Somewhat similar behavior is observed for Chouto and Pavia (not shown), where differences in the mean are large. Contrasting, smaller differences are observable for Évora, in the south and at low altitude. The other southern inland stations show a behavior similar to Évora. Similarly to Porto, Lisboa and Faro, other southern stations, excepting Chouto and Pavia, show a behavior marked by the changes in pdf during 191143 (left panel of Fig. 3). These differences also appear in the cdfs, on the right panel of Fig. 3. In the station of Montalegre the cdf curves of the initial sub-periods are nearly superposed while the curves of the more recent sub-periods of 1944-75 and 1976-2007 are somewhat distant with the cdf relative to the full period lying in the middle, so reflecting the average conditions over the complete time of records. Differently, all other stations show cdf curves closer than in Montalegre. This indicates a smaller variability of precipitation, which is also evident from Fig. 2 and Table 3.

In Montalegre the median, i.e., the 12 -month precipitation corresponding to a 0.5 cumulative probability, is higher for recent conditions. Generally, with exception for Évora, precipitation with higher non-exceedance probabilities in 1911-43 are lower than for other sub-periods as shown by the cdfs on the right panel of Fig. 3. However, as referred before, differences among sub-periods are smaller than for Montalegre. 

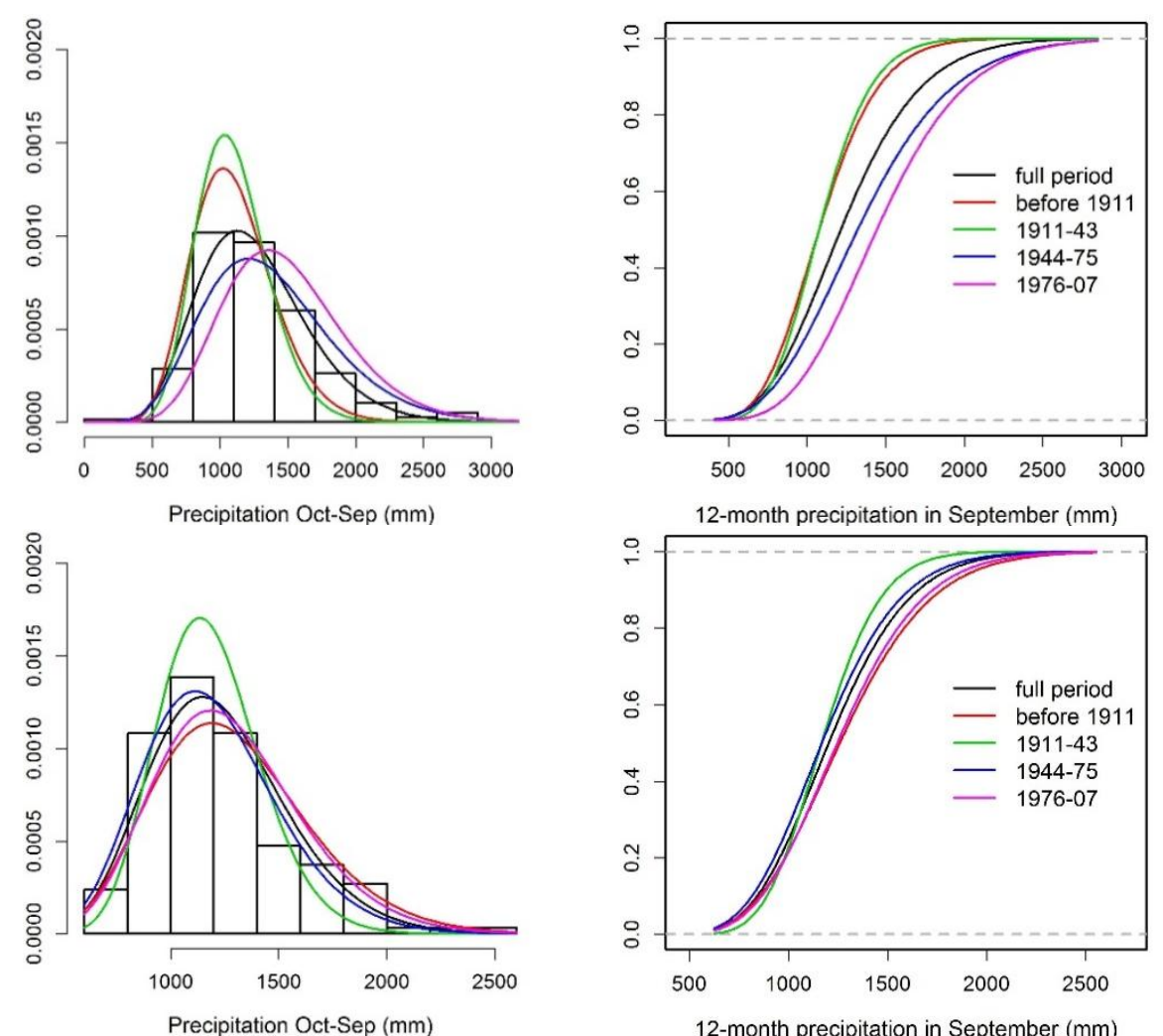

Montalegre
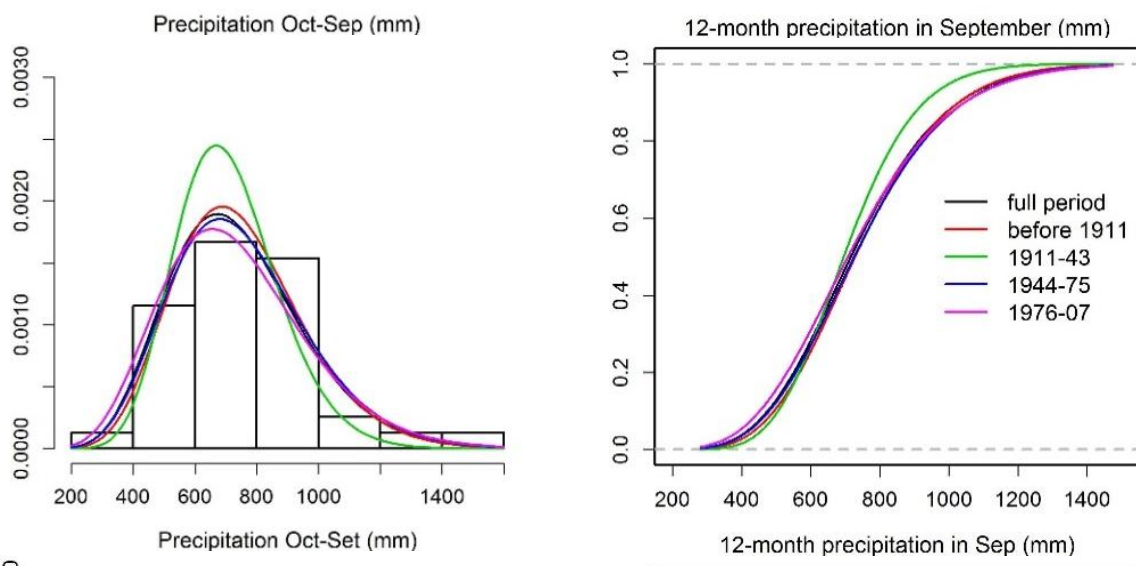

Porto
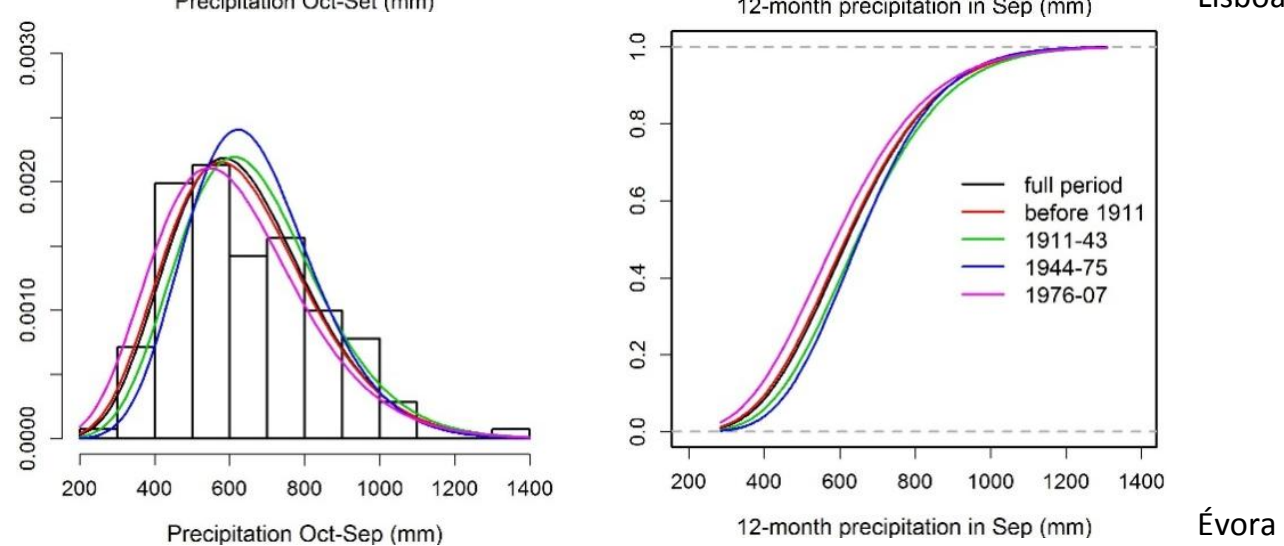

300 Figure 3. Gamma probability distribution functions (on left) and cumulative distribution functions (on right) of annual 301 precipitation cumulated from October to September for the full data records and the four sub-periods for Montalegre, Porto, Lisboa and Évora. The histogram of the precipitation frequencies for the full period is also shown 


\subsection{Changes in SPI precipitation thresholds}

A zoom of the lower tail of the cdfs relative to October-September is presented in Fig. 4 relative to the four stations having longer periods of records. The zoom allows to identify the SPI precipitation thresholds relative to moderate, severe and extreme droughts. These values correspond to the interception of the SPI horizontal lines with the cdf curves relative to the full period and the sub-periods. For a given location, the horizontal distance between two interception points relative to the various drought categories corresponds to the difference in precipitation for the considered subperiods relative to the SPI thresholds. When differences in precipitation among sub-periods are large than the difference of the thresholds are also large. When the precipitation threshold values increase (decrease) this means that a given drought category is attained for a larger (smaller) precipitation than before.

The distances between cdf curves at the lower tail are higher in Montalegre (and Chouto, not shown). Conversely, differences are smaller in Lisbon and Porto (and Beja, not shown). Montalegre is the location where the cdf curves of the various periods show an increase in the SPI precipitation thresholds from the earlier to the last period. A moderate drought was identified for $806 \mathrm{~mm}$ in the period prior to 1911 while for the last period, 1976-2007, that amount increased to $1046 \mathrm{~mm}$ (Table 4). For the severe droughts, the threshold increased for the same periods from 690 to $878 \mathrm{~mm}$. This behavior is due to an increase of precipitation as identified in Fig. 2 and through trend analysis. Due to that increase, the month September 1989, with a 12-month cumulated precipitation of $832 \mathrm{~mm}$, thus between the precipitation thresholds 731 and $878 \mathrm{~mm}$ (Table 4) relative to SPI=-1.5 and SPI=1 and identified as severely dry, would be classified as moderately dry if the full period threshold interval, $711 \mathrm{~mm}$ to $859 \mathrm{~mm}$, was applied. Differently, for Porto changes in precipitation thresholds among the four sub-periods are small (Fig. 4). For Lisboa, Évora and Beja the precipitation thresholds increase and decrease through the considered sub-periods but the threshold relative to the last period is the small one. This may indicate a variable trend in annual precipitation depths. In Lisbon a severe drought was identified for a threshold of $459 \mathrm{~mm}$ prior to 1911 while for the latest period that threshold decreased to $416 \mathrm{~mm}$ (Table 5); for Porto, there is a small increase, from 795 to $807 \mathrm{~mm}$, and for Évora there is a decrease from 373 to $343 \mathrm{~mm}$.

For all other stations, the smaller precipitation thresholds for the three drought categories generally refer to the period of 1911-43 and the larger ones refer to 1944-75. When considering the extreme drought category the comparison among sub-periods is generally similar to that for severe droughts. A possible interpretation is that droughts are probably not aggravating but they are somewhat responding to some cyclic variation as per the analysis performed by Moreira et al. (2012), also in agreement with the trend analysis performed by Santos et al. (2010), Martins et al. (2012), Paulo et al. (2012) and Raziei et al. (2015). However, despite there is no evidence of 
aggravation of droughts in terms of SPI values, the meaning of the category of drought is certainly different when, for instance, a severe drought in Évora was attained when the precipitation was not 343 above $408 \mathrm{~mm}$, in 1911-43, and later was attained if precipitation did not exceed $343 \mathrm{~mm}$. In fact, 344 that difference of $65 \mathrm{~mm}$ may indicate that impacts of a severe drought have increased with the 345 decrease of the precipitation. It is likely that instead of using a probabilistic and standardized 346 drought index results could be different when using a deterministic and standardized index like PDSI or MedPDSI that determine the departure from normal conditions through a water balance using precipitation and evapotranspiration data.
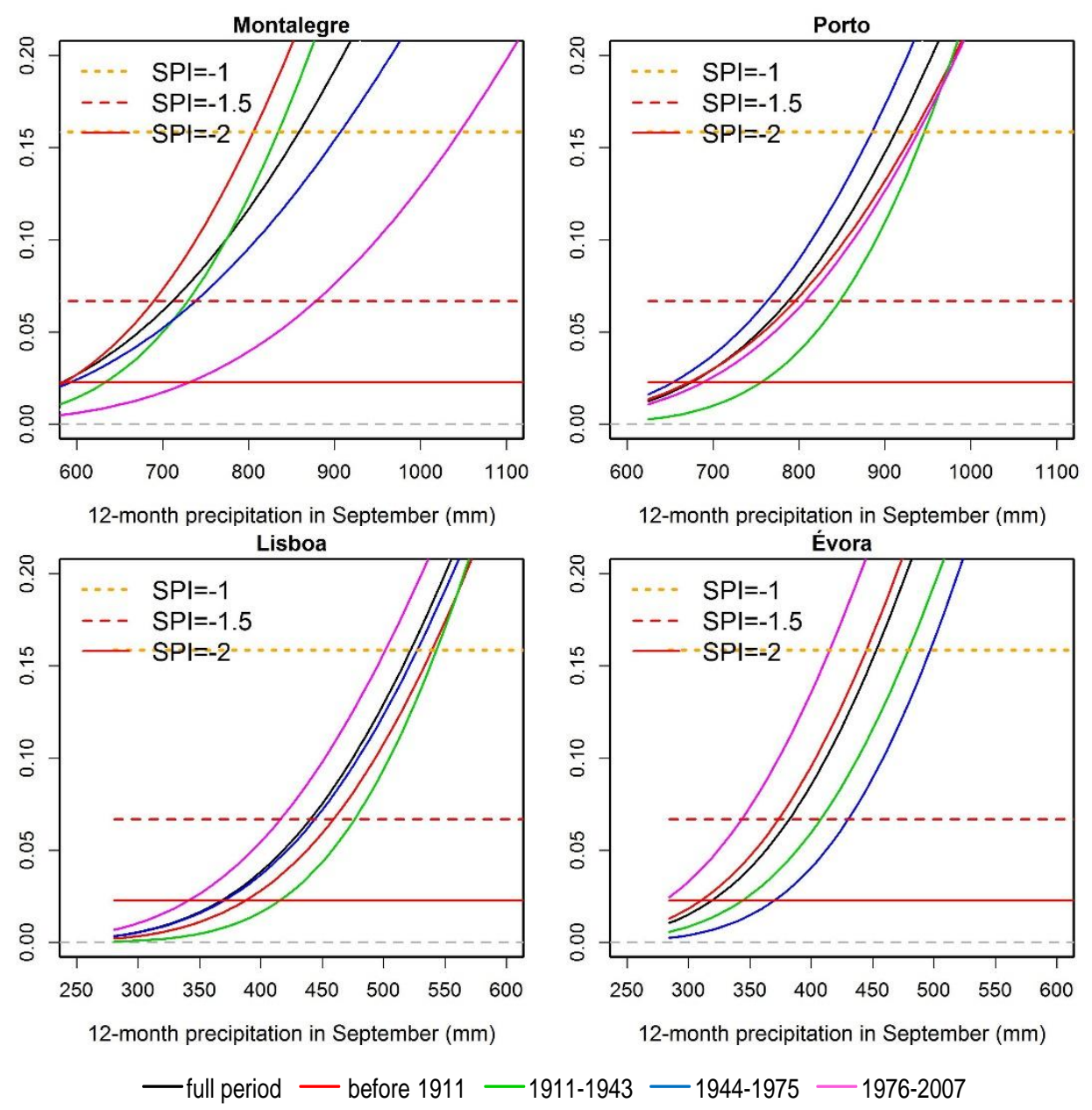

Figure 4. Zoom on the lower tail of the gamma cumulative distribution functions of Montalegre, Porto, Lisboa and Évora for the full period of records and four sub-periods with identification of the related SPI-12 thresholds of moderate, severe and extreme drought categories relative to the 12-month precipitation from October to September. 
Table 5. Precipitation thresholds ( $\mathrm{mm}$ ) corresponding to SPI-12=0 (median), SPI-12=-1, -1.5, -2 (moderate, severe and extreme drought categories) computed for September with the full records and respective sub-periods for all stations.

\begin{tabular}{|c|c|c|c|c|c|c|c|c|c|c|}
\hline \multirow[b]{2}{*}{ SPI } & \multirow[b]{2}{*}{ Period } & \multicolumn{9}{|c|}{ Meteorological stations } \\
\hline & & Montal. & Porto & Chouto & Pavia & Lisboa & Évora & Beja & S.Brás & Faro \\
\hline \multirow[t]{5}{*}{0} & Total & 1214 & 1208 & 699 & 536 & 716 & 621 & 552 & 782 & 448 \\
\hline & Before 1911 & 1077 & 1258 & - & - & 728 & 615 & - & - & - \\
\hline & $1911-43$ & 1076 & 1167 & 641 & 485 & 695 & 647 & 537 & 752 & 387 \\
\hline & $1944-75$ & 1321 & 1168 & 810 & 593 & 725 & 651 & 567 & 839 & 489 \\
\hline & 1976-07 & 1443 & 1246 & 685 & 557 & 707 & 588 & 546 & 812 & 479 \\
\hline \multirow[t]{5}{*}{-1} & Total & 859 & 916 & 481 & 374 & 522 & 453 & 413 & 534 & 295 \\
\hline & Before 1911 & 806 & 934 & - & - & 539 & 445 & - & - & - \\
\hline & $1911-43$ & 835 & 946 & 408 & 334 & 543 & 479 & 415 & 556 & 272 \\
\hline & 1944-75 & 907 & 885 & 616 & 436 & 527 & 497 & 425 & 603 & 325 \\
\hline & 1976-07 & 1046 & 939 & 497 & 386 & 502 & 415 & 382 & 537 & 301 \\
\hline \multirow[t]{5}{*}{-1.5} & Total & 711 & 790 & 391 & 308 & 440 & 382 & 354 & 433 & 234 \\
\hline & Before 1911 & 690 & 795 & - & - & 459 & 373 & - & - & - \\
\hline & $1911-43$ & 729 & 847 & 317 & 272 & 476 & 408 & 362 & 473 & 224 \\
\hline & $1944-75$ & 738 & 763 & 532 & 370 & 444 & 430 & 364 & 505 & 260 \\
\hline & 1976-07 & 878 & 807 & 418 & 316 & 416 & 343 & 315 & 428 & 232 \\
\hline \multirow[t]{5}{*}{-2} & Total & 583 & 677 & 315 & 250 & 368 & 319 & 300 & 346 & 183 \\
\hline & Before 1911 & 586 & 672 & - & - & 388 & 310 & - & - & - \\
\hline & $1911-43$ & 633 & 756 & 242 & 219 & 415 & 344 & 313 & 399 & 182 \\
\hline & $1944-75$ & 593 & 653 & 456 & 311 & 370 & 370 & 310 & 418 & 204 \\
\hline & 1976-07 & 731 & 688 & 348 & 256 & 341 & 281 & 256 & 335 & 175 \\
\hline
\end{tabular}

Observing the series of SPI-12 in Montalegre, Porto, Évora and Lisboa (Fig. 5) computed for the full period and for each sub-period it is possible to observe a disagreement between the SPI-12 computed for the full data set and for the sub-periods. At Montalegre, the first two sub-periods, prior to 1911 and 1911-1943, have higher SPI values when they are computed with the sub-periods data, inversely during the later sub-periods. This behaviour relates with the referred changes in the drought (and wetness) precipitation thresholds as analysed before. This result highlights an apparent increase of precipitation at Montalegre in the more recent time periods.

The SPI series for Porto behave similarly but with less evidence of changes; differently, for Lisboa and Évora there is a better agreement between SPI computed from the pdf adjusted for the full period and for the sub-periods, meaning that normal precipitation patterns are similar in the full period and sub-periods. Briefly if the SPI values in recent periods are lower/higher when using the full period as reference period instead of the sub-periods then a recent downward/upward shift of precipitation may have occurred. The 'normal' conditions are therefore changing and an update of the SPI calculation should be considered. This could be particularly important when comparing past conditions with future if changes in precipitation are foreseen for future; it is then likely that SPI thresholds will be different, which may lead to biased interpretations of changes in droughts. 

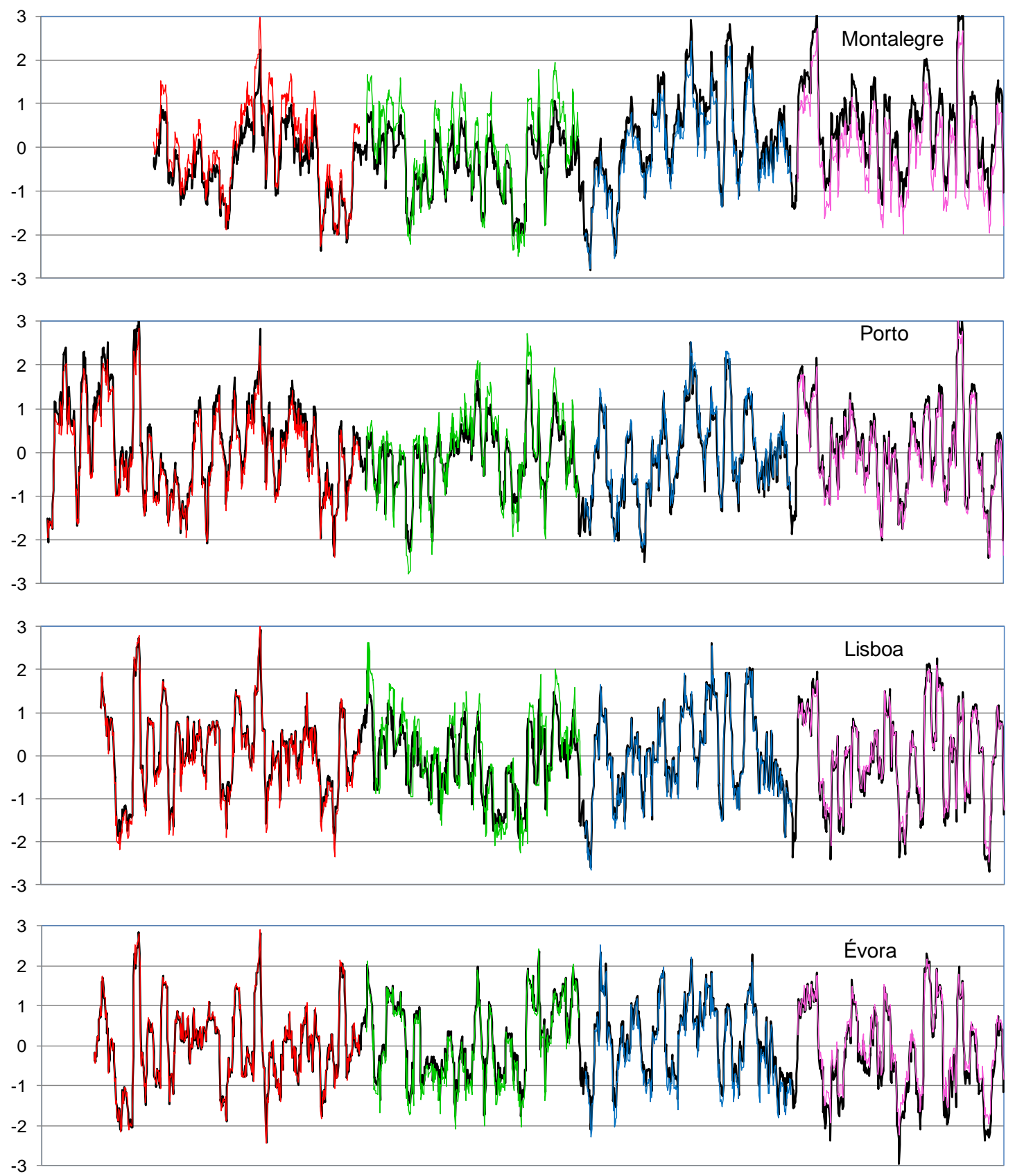

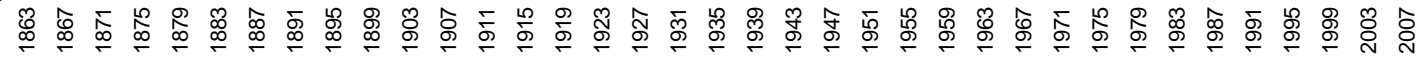

— full period — before $1911 \_$1911-1943 -1944-1975 - 1976-2007

Figure 5. SPI-12 at Montalegre, Porto, Évora and Lisboa computed for the full data period and for the sub-periods.

\subsection{Changes in the percentage of time in SPI categories}

Changes in drought severity can be noticed when comparing the changes in the percentage of time in the drought categories of the full reference SPI series as well comparing with those of the sub-periods (Table 6). Related changes in the SPI-12 time series for the full reference period and the sub-periods are shown in Fig. 5 for Montalegre, Porto, Évora and Lisboa. The full period time series for Montalegre shows a marked difference between the full-period SPI-12 time series (black 
line) relative to the SPI-12 time series of the various sub-periods, the decrease of the percent of time

387 in the more severe drought categories, and severe or extremely dry months do not occur since 1950.

388 For the other locations there is not a persistent change signal, with alternate periods of more severe 389 drought/wetness.

390 The percentage of time in moderate and more severe (combined severe and extreme) drought and 391 wetness categories for each time period is shown in Table 6 for the nine stations using as reference 392 period the full record and each sub-period. The 1911-43 and the more recent time period, 19763932007 show greater differences on the percentage of time in the SPI categories.

Table 6. Comparing the percentage of time in moderate, severe and extreme drought/wetness categories for the full period of records and the various sub-periods.

\begin{tabular}{|c|c|c|c|c|c|c|c|c|c|c|c|c|}
\hline \multirow{2}{*}{$\begin{array}{l}\text { Time } \\
\text { Sub-period }\end{array}$} & \multirow{2}{*}{\multicolumn{2}{|c|}{ SPI category }} & \multirow[t]{2}{*}{ Reference } & \multicolumn{9}{|c|}{ Meteorological Stations } \\
\hline & & & & Montal & Porto & Chouto & Pavia & Lisboa & Évora & Beja & Faro & S.Brás \\
\hline \multirow{8}{*}{$1879-1910$} & \multirow[t]{4}{*}{ Dry } & \multirow[t]{2}{*}{ Extr+Sev } & Full period & $10 \%$ & $5 \%$ & - & - & $5 \%$ & $6 \%$ & - & - & - \\
\hline & & & Sub-period & $9 \%$ & $6 \%$ & - & - & $8 \%$ & $6 \%$ & - & - & - \\
\hline & & \multirow[t]{2}{*}{ Moder } & Full period & $12 \%$ & $10 \%$ & - & - & $9 \%$ & $10 \%$ & - & - & - \\
\hline & & & Sub-period & $8 \%$ & $12 \%$ & - & - & $10 \%$ & $9 \%$ & - & - & - \\
\hline & \multirow[t]{4}{*}{ Wet } & \multirow[t]{2}{*}{ Moder } & Full period & $3 \%$ & $12 \%$ & - & - & $9 \%$ & $5 \%$ & - & - & - \\
\hline & & & Sub-period & $12 \%$ & $10 \%$ & - & - & $8 \%$ & $4 \%$ & - & - & - \\
\hline & & \multirow[t]{2}{*}{ Extr+Sev } & Full period & $1 \%$ & $12 \%$ & - & - & $6 \%$ & $8 \%$ & - & - & - \\
\hline & & & Sub-period & $6 \%$ & $7 \%$ & - & - & $6 \%$ & $9 \%$ & - & - & - \\
\hline \multirow[t]{8}{*}{$1911-1943$} & \multirow[t]{4}{*}{ Dry } & \multirow[t]{2}{*}{ Extr+Sev } & Full period & $10 \%$ & $5 \%$ & $10 \%$ & $11 \%$ & $5 \%$ & $1 \%$ & $5 \%$ & $6 \%$ & $5 \%$ \\
\hline & & & Sub-period & $11 \%$ & $7 \%$ & $7 \%$ & $10 \%$ & $10 \%$ & $4 \%$ & $6 \%$ & $4 \%$ & $6 \%$ \\
\hline & & \multirow[t]{2}{*}{ Moder } & Full period & $8 \%$ & $7 \%$ & $13 \%$ & $10 \%$ & $9 \%$ & $8 \%$ & $10 \%$ & $16 \%$ & $11 \%$ \\
\hline & & & Sub-period & $6 \%$ & $8 \%$ & $5 \%$ & $4 \%$ & $6 \%$ & $17 \%$ & $10 \%$ & $11 \%$ & $12 \%$ \\
\hline & \multirow[t]{4}{*}{ Wet } & \multirow[t]{2}{*}{ Moder } & Full period & $0 \%$ & $5 \%$ & $7 \%$ & $5 \%$ & $8 \%$ & $13 \%$ & $10 \%$ & $4 \%$ & $6 \%$ \\
\hline & & & Sub-period & $13 \%$ & $6 \%$ & $10 \%$ & $11 \%$ & $10 \%$ & $12 \%$ & $11 \%$ & $8 \%$ & $10 \%$ \\
\hline & & \multirow[t]{2}{*}{ Extr+Sev } & Full period & $0 \%$ & $2 \%$ & $5 \%$ & $3 \%$ & $1 \%$ & $8 \%$ & $2 \%$ & $3 \%$ & $2 \%$ \\
\hline & & & Sub-period & $3 \%$ & $7 \%$ & $5 \%$ & $5 \%$ & $7 \%$ & $6 \%$ & $8 \%$ & $8 \%$ & $7 \%$ \\
\hline \multirow[t]{8}{*}{$1944-1975$} & \multirow[t]{4}{*}{ Dry } & \multirow[t]{2}{*}{ Extr+Sev } & Full period & $6 \%$ & $8 \%$ & $0 \%$ & $2 \%$ & $6 \%$ & $2 \%$ & $6 \%$ & $5 \%$ & $4 \%$ \\
\hline & & & Sub-period & $6 \%$ & $6 \%$ & $5 \%$ & $6 \%$ & $6 \%$ & $5 \%$ & $6 \%$ & $7 \%$ & $6 \%$ \\
\hline & & \multirow[t]{2}{*}{ Moder } & Full period & $5 \%$ & $12 \%$ & $2 \%$ & $6 \%$ & $10 \%$ & $8 \%$ & $8 \%$ & $5 \%$ & $7 \%$ \\
\hline & & & Sub-period & $8 \%$ & $9 \%$ & $13 \%$ & $8 \%$ & $8 \%$ & $15 \%$ & $10 \%$ & $10 \%$ & $9 \%$ \\
\hline & \multirow[t]{4}{*}{ Wet } & \multirow[t]{2}{*}{ Moder } & Full period & $11 \%$ & $9 \%$ & $15 \%$ & $15 \%$ & $10 \%$ & $15 \%$ & $12 \%$ & $17 \%$ & $14 \%$ \\
\hline & & & Sub-period & $8 \%$ & $11 \%$ & $13 \%$ & $12 \%$ & $10 \%$ & $11 \%$ & $12 \%$ & $14 \%$ & $11 \%$ \\
\hline & & \multirow[t]{2}{*}{ Extr+Sev } & Full period & $13 \%$ & $6 \%$ & $9 \%$ & $9 \%$ & $9 \%$ & $6 \%$ & $7 \%$ & $8 \%$ & $7 \%$ \\
\hline & & & Sub-period & $9 \%$ & $7 \%$ & $7 \%$ & $9 \%$ & $9 \%$ & $6 \%$ & $6 \%$ & $3 \%$ & $6 \%$ \\
\hline \multirow[t]{8}{*}{$1976-2007$} & Dry & Extr+Sev & Full period & $0 \%$ & $5 \%$ & $3 \%$ & $6 \%$ & $13 \%$ & $17 \%$ & $15 \%$ & $8 \%$ & $7 \%$ \\
\hline & & & Sub-period & $4 \%$ & $5 \%$ & $8 \%$ & $6 \%$ & $7 \%$ & $6 \%$ & $8 \%$ & $8 \%$ & $7 \%$ \\
\hline & & Moder & Full period & $5 \%$ & $10 \%$ & $12 \%$ & $8 \%$ & $9 \%$ & $10 \%$ & $4 \%$ & $7 \%$ & $10 \%$ \\
\hline & & & Sub-period & $17 \%$ & $12 \%$ & $10 \%$ & $11 \%$ & $12 \%$ & $12 \%$ & $10 \%$ & $8 \%$ & $12 \%$ \\
\hline & Wet & Moder & Full period & $16 \%$ & $11 \%$ & $10 \%$ & $13 \%$ & $13 \%$ & $13 \%$ & $10 \%$ & $10 \%$ & $13 \%$ \\
\hline & & & Sub-period & $8 \%$ & $10 \%$ & $11 \%$ & $14 \%$ & $11 \%$ & $15 \%$ & $9 \%$ & $5 \%$ & $10 \%$ \\
\hline & & Extr+Sev & Full period & $15 \%$ & $8 \%$ & $3 \%$ & $10 \%$ & $8 \%$ & $6 \%$ & $11 \%$ & $10 \%$ & $11 \%$ \\
\hline & & & Sub-period & $7 \%$ & $6 \%$ & $7 \%$ & $6 \%$ & $6 \%$ & $6 \%$ & $8 \%$ & $7 \%$ & $7 \%$ \\
\hline
\end{tabular}


In 1976-2007 a disagreament between the percentage of months in the more severe drought categories when using the full period and the sub-period as reference can be observed in some 401 stations. In Montalegre, when the gamma distribution is obtained from the centennial record, the frequency of severe and extreme drought months in the time period 1976-2007 is 0\% and the percentage of time in moderate drought is $5 \%$, corresponding to only 18 months in 32 years of the sub-period. From the perspective of present, when considering 1976-2007 as reference for the computation of SPI results are quite different with $4 \%$ of time under more severe drought and $17 \%$ with moderate drought. Using the full period as reference, $16 \%$ of time in moderate wetness and $15 \%$ in more wet categories have been identified, thus contrasting with the drought conditions. 408 These results, dictated by a 128 years long precipitation record having a significant positive trend, would identify 1976-2007 as a wet period. Differently, deriving the SPI from data relative to that period, a moderate wetness is identified for $8 \%$ of time and more wet conditions for $7 \%$ only. These 411 results indicate that the frequency of droughts (wetness) identified through the time in each category 412 are substantially different when the SPI is computed from the full data record or from the more 413 recent period of observations. This behaviour is coherent with issues discussed before and reflects 414 the detected changes in precipitation. The behaviour for Faro, where an increased precipitation 415 trend was detected, is somewhat similar but mitigated because changes in precipitation are smaller than at Montalegre.

For Porto differences in the frequency of drought (wetness) events when the SPI is computed from full data or from sub-periods data are relatively small. In the previous analysis it was observed that differences in precipitation thresholds were small, which may justify that behaviour.

In Évora, the SPI obtained from the full precipitation record identifies as dry (moderate or more severe) $10 \%$ of the months in the time periods $1911-43$ and $1944-75$ and $27 \%$ in 1976-2007, very different from the balanced percentages of $21 \%, 20 \%$ and $18 \%$ relative to the SPI sub-period time series. Particularly in 1976-2007, 17\% of months were identified as severe or extremely dry with the full record and that frequency decays to 6\% under 1976-2007 gamma distribution of precipitation. The results obtained for the full record parametrization may be explained by the negative but not significant trends observed in precipitation (not shown). In Lisboa and Beja, in the later period, the SPI obtained from the full record identifies $13 \%$ of the months as severe or extremely dry in Lisboa and 15\% in Beja while for the sub-period those percentages decrease to $7 \%$ in Lisboa and $8 \%$ in Beja. An over estimation of drought frequencies in the later period by the full record distribution may indicate a recent precipitation decrease, which is also concordant with the decrease of the precipitation thresholds of drought categories in 1976-2007. For Chouto, when using the pdf adjusted to the full records a $2 \%$ frequency of the moderate or more severely drought months in the second period, 1944-75, which contrasts with the $23 \%$ occurrence in the period 1911- 
43443 and $15 \%$ in the more recent period; differently, it remains almost the same when pdfs are 435 computed for the sub-periods. Pavia presents approximately the same tendencies for the 1911-43 436 and 1944-75 sub-periods. In S. Brás de Alportel, in South, there is a better agreement between the 437 percentage of severe drought months for the full period and the sub-periods; however the first 438 period is characterized by a marked difference relative to the wettest months, $8 \%$ for the pdf of the 439 full record versus $17 \%$ for pdf of the sub-period.

440 These results show drought frequency similarities between alternate sub-periods in Chouto and 441 Pavia and dissimilarities between the consecutive 1944-75 and 1976-2007 time periods in Évora, 442 Beja and Lisboa relative to the percentage of severe drought months when considering a unique SPI 443 time series.

\section{Conclusions}

The influence of the reference period in the SPI-12 computation was explored using long time series of precipitation segmented in sub-periods. Results have shown that when SPI values derived from the full data record for a recent time period are lower/higher than the SPI values derived from data of the considered time period a recent downward/upward shift of precipitation has occurred. The estimation of the precipitation thresholds for the moderate, severe and extreme drought categories, corresponding to $\mathrm{SPI}=-1, \mathrm{SPI}=-1.5$ and $\mathrm{SPI}=-2$, complemented the information provided by the SPI. The joint plotting of the pdf and cdf computed for the full period and the different subperiods allowed a visual comparison of the distributions and allowed to perceive that large differences in the SPI precipitation thresholds would be justified.

It was observed that long-term precipitation variability is reflected on the precipitation thresholds in different periods. The changes in precipitation from the initial until the more recent time period in locations where a positive trend holds, e.g. Montalegre, lead to higher drought precipitation thresholds; thus, a recent severe drought would be classified as moderate when the pdf would be adjusted to the full period of records.

In most of the stations, excepting the northern stations of Porto and Montalegre, the precipitation thresholds relative to a given drought category in the more recent period 1976-2007 are lower than in the precedent period likely meaning that a downward shift in precipitation may have occurred. The differences between the severe precipitation thresholds in the more recent and in the precedent period range from $-140 \mathrm{~mm}$ in Montalegre to $114 \mathrm{~mm}$ in Chouto, therefore showing positive values in the southern stations, thus reflecting a possible decrease in precipitation. An over estimation of drought frequencies in the later period by the full record distribution was observed in Lisboa, Évora and Beja, which may also reflect a recent decrease in precipitation. 
In conclusion, under persistent or cyclic changes in precipitation and when long precipitation time series are available, using the complete record as reference period to derive 'normal conditions' for SPI computation masks the actual precipitation deficits/surplus. If precipitation changes are expected, such as in studies aimed at analysing future climate changes, the parametrization of the precipitation distribution and the SPI computation using as reference a period referring to the more recent or the studied climate, along with the estimation of precipitation severity thresholds, should be considered. Thus, results obtained herein, may point to a new approach in climate change studies that surpass the limitations inherent to using the SPI monthly pdfs of present climate to model future climates.

The problems detected using SPI are due to its probabilistic nature and may not be such if using a semi-deterministic index as PDSI (or MedPDSI) since these indices combine precipitation and evapotranspiration into a water balance to detect the departure from normal conditions. This approach could be adopted relative to assess impacts of future scenarios of climate change but are difficult to apply when comparing different sub-periods of calculations because weather data used for evapotranspiration calculations are generally scarce. However, this is a future objective of study.

\section{Acknowledgements}

This study was funded by a research contract with FCT, Portugal, nr. PTDC/GEO-MET/ 410 3476/2012. The first author thanks the fellowship number SFRH/BD/92880/2013, awarded to the second author.

\section{References}

Bordi I, Sutera A (2001). Fifty years of precipitation: Some spatially remote teleconnections, Water Resour. Manag., 15, 247-280.

D'Agostino R B, Stephens M A (1986). Goodness-of-fit techniques. Series: Statistics, Text Books and Monographs; vol.68, $560 \mathrm{p}$.

Dai A (2011) Drought under global warming: A review. WIREs Climate Change 2, 45-65.

de Lima, M I P, Carvalho S C P, de Lima J L M P, Coelho M F E S (2010) Trends in precipitation: analysis of long annual and monthly time series from mainland Portugal, Adv Geosci 25, 155-160.

de Lima M I P, Santo F E, Ramos A M, Trigo R M (2015) Trends and correlations in annual extreme precipitation indices for mainland Portugal, 1941-2007. Theor Appl Climatol 119:55-75.

Dubrovsky M, Svoboda M D, Trnka M, Hayes M J, Wilhite D A, Zalud Z, Hlavinka P (2009) Application of relative drought indices in assessing climate-change impacts on drought conditions in Czechia. Theor Appl Climatol 96:155-171.

Guttman NB (1999) Accepting the Standardized Precipitation Index: A calculation algorithm. J Am Water Resour Assoc 35, 311-322.

Jeong D I, Sushama L, Khaliq M N (2014) The role of temperature in drought projections over North America, Climatic Change (2014) 127:289-303.

Keyantash J, Dracup J A (2002) The quantification of drought: an evaluation of drought indices. Bull. Amer. Meteor Soc., 83(8), pp. 1167-1180.

Loukas A, Vasiliades L, Tzabiras J (2008) Climate change effects on drought severity. Adv Geosci 17, 2329. 
Martins D S, Raziei T, Paulo A A, Pereira LS (2012). Spatial and temporal variability of precipitation and drought in Portugal. Nat. Hazards Earth Syst. Sci., 12, 1493-150

McKee T B, Doesken N J, Kleist J (1993) The relationship of drought frequency and duration of time scales. 8th Conference on Applied Climatology, Am. Meteor. Soc., Boston, 179-186.

McKee T B, Doesken N J, Kleist J. (1995). Drought monitoring with multiple time scales. In: 9th Conference on Applied Climatology, Am. Meteor. Soc., Boston, pp. 233-236.

Mishra A K, Singh V P (2010) A review of drought concepts. J Hydrol 391, 202-216.

Moreira E E, Mexia J T, Pereira L S (2012) Are drought occurrence and severity aggravating? A study on SPI drought class transitions using log-linear models and ANOVA-like inference. Hydrol Earth Syst Sci 16, 3011-3028.

Palmer W C (1965) Meteorological Drought, Research Paper No. 45, US Department of Commerce, Weather Bureau, Washington, DC.

Paulo A A, Pereira L S, Matias P G (2003) Analysis of local and regional droughts in southern Portugal using the theory of runs and the Standardized Precipitation Index, in: Tools for Drought Mitigation in Mediterranean Regions, edited by: G Rossi, A Cancelliere, L S Pereira, T Oweis, M Shatanawi, A Zairi, Kluwer, Dordrecht, 55-78.

Paulo A A, Pereira L S (2006) Drought concepts and characterization: comparing drought indices applied at local and regional scales, Water Int 31, 37-49.

Paulo A A, Pereira L S (2008) Stochastic prediction of drought class transitions. Water Resour Manage 22: 1277-1296.

Paulo A A, Rosa R D, Pereira L S (2012) Climate trends and behaviour of drought indices based on precipitation and evapotranspiration in Portugal. Nat Hazards Earth Syst Sci 12, 1481-1491.

Pereira L S, Rosa R D, Paulo A A (2007) Testing a Modification of the Palmer Drought Severity Index for Mediterranean Environments, in: Methods and Tools for Drought Analysis and Management, edited by: G Rossi, T Vega, B Bonaccorso, Springer, Dordrecht, 149-167.

Pereira L S, Cordery I, Iacovides I (2009) Coping with Water Scarcity. Addressing the Challenges. Springer, Dordrecht, $382 \mathrm{p}$.

Portela M M, Santos J F F, Naghettini N, Matos J P, Silva A T (2012) Superfícies de limiares de precipitação para identificação de secas em portugal continental: uma aplicação complementar do índice de precipitação padronizada, SPI. Recursos Hídricos 33(02), 5-23.

Raziei T, Martins D S, Bordi I, Santos J F, Portela M M, Pereira L S, Sutera A (2015) SPI Modes of Drought Spatial and Temporal Variability in Portugal: Comparing Observations, PT02 and GPCC Gridded Datasets. Water Resour Manage 29:487-504.

Rhoades D A, Salinger M J (1993) Adjustment of temperature and rainfall records for site changes. Int. J Climatol 13: 899-913.

Russo S, Dosio A, Sterl A, Barbosa P, Vogt J (2013) Projection of occurrence of extreme dry-wet years and seasons in Europe with stationary and nonstationary Standardized Precipitation Indices. J Geophys Res Atmos 118, 7628-7639.

Santos J F, Pulido-Calvo I, Portela M M (2010) Spatial and temporal variability of droughts in Portugal. Water Resour Res 46, W03503.

Sienz F, Bothe O, Fraedrich K (2012) Monitoring and quantifying future climate projections of dryness and wetness extremes: SPI bias. Hydrol Earth Syst Sci 16, 2143-2157

Vicente-Serrano S M, (2006). Spatial and temporal analysis of droughts in the Iberian Peninsula (19102000), Hydrolog Sci J, 51, 83-97.

Wang Y, Li J, Feng P, Hu R (2015) A time-dependent drought index for non-stationary precipitation series. Water Resour Manage 29:5631-5647.

World Meteorological Organization (2012) Standardized Precipitation Index User Guide (M. Svoboda, M. Hayes and D. Wood). (WMO-No. 1090), Geneva.

Wu H, Svoboda M, Hayes M J, Wilhite D A, Wen F (2007) Appropriate application of the Standardized Precipitation Index in arid locations and dry seasons. Int J Climatol 27: 65-79.

Zarch M A A, Sivakumar B, Sharma A (2015) Droughts in a warming climate: A global assessment of Standardized Precipitation Index (SPI) and Reconnaissance Drought Index (RDI). J Hydrol 526:183-195 
560 Zargar A, Sadiq R, Khan F I (2014) Uncertainty-driven characterization of climate change effects on drought 561 frequency using enhanced SPI. Water Resour Manage. 28:15-40 